Journal of Advanced Research in Fluid Mechanics and Thermal Sciences

Journal homepage: www.akademiabaru.com/arfmts.html ISSN: 2289-7879

\title{
Temperature and Concentration Dependent Viscosity of Microcrystalline Cellulose in Water
}

\author{
Wan Nor Suhaila Wan Aziz ${ }^{1,2}$, Shahrul Kadri Ayop ${ }^{2,}{ }^{*}$, Rosazley Ramly ${ }^{2}$ \\ 1 Unit Kawalselia Radiasi Perubatan, Pahang State Health Department, Jalan IM/4, Bandar Indera Mahkota, 25582, Kuantan, Pahang, Malaysia \\ 2 The Department of Physics, Faculty of Science and Mathematics, Sultan Idris Education University, 35900 Tanjong Malim, Perak, Malaysia
}

\section{ARTICLE INFO ABSTRACT}

\section{Article history:}

Received 25 September 2020

Received in revised form 13 January 2021

Accepted 15 January 2021

Available online 15 February 2021

Keywords:

Viscosity; magnetic bearing rheometer; cellulose; microcrystalline

\begin{abstract}
The viscosity of cellulose behaves differently and uniquely in various conditions. In this paper, we aim to report the viscosity measurement and related properties of low concentration of microcrystalline cellulose (MCC) in water using a magnetic bearing rheometer. Dynamic viscosities for MCC diluted in water at varying concentrations were measured using the standard rheometry technique. The viscosity of the MCC solution was found highly dependent on its concentration and the experiment temperature. This varieties behaviour and properties offers benefits to the current growing rapidly technology applications such as in food, pharmaceutical cosmetics and textile.
\end{abstract}

\section{Introduction}

Microcrystalline cellulose (MCC) is widely used in various industrial fields such as medicine, cosmetics, pharmaceuticals and polymer composite [1-7]. Recently due to its novelty, non-toxicity properties, economic value, biodegradation, mechanical properties, surface area and biocompatibility, the interest on MCC have increased [1-7]. For example, the properties of hydrogels facilitate their usage in bio-related applications, including drug delivery systems, tissueengineering scaffolds, wound dressing, and biomedical devices [8-12]. The imperfect mechanical properties of hydrogels would give limitations for applications that require high strength properties $[8,13]$. Therefore, cellulose can be act as a suitable biopolymer for synthesizing a hydrogel to have outstanding mechanical properties [8]. Due to the inherent crystalline structure, cellulose exhibits high strength, high stiffness, and low density [14]. It is potentially possible to synthesize the highstrength microcrystalline cellulose hydrogel by controlling the viscosity of cellulose solutions [8]. The information of viscosity of MCC is essential for a small scale to industrial scale in a diverse field in order to optimize the output quality and can affect directly to the final product [2].

\footnotetext{
* Corresponding author.

E-mail address: shahrul.kadri@fsmt.upsi.edu.my
}

https://doi.org/10.37934/arfmts.80.2.7481 
Furthermore, the estimation level of carbohydrate degradation caused by pulping and bleaching steps could use the viscosity information as a control parameter of cellulose pulp quality [15]. The resulting viscosity of a fully bleached cellulose pulp showed that substantially lower than unbleached cellulose pulp, which contributes to the lower paper strength properties $[15,16]$. The previous study has shown that less degraded bleached cellulose pulps that combined higher viscosities and residual lignin contents would have lower water absorption and vice versa as the determination of water absorption is essential information for packaging and printing industries [15].

The viscosity affects significantly the abundance of air-water with glycerin that clings to the inner walls of the pipe and higher concentration of glycerin in the liquid would increase the wave and stuck as reported in two-phase flow in mini pipe simulation [17]. The consideration of twophase flow in mini pipe are important in design and development in industrial and medical applications, such as micro heat exchangers, micro cooling electronics and bio-micro-electro mechanical system [17]. In automobile and domestic application, currently the fossil diesel mixed with biodiesel through blending process before any usage. The biodiesel density and viscosity are the influence factors for diesel biodiesel mixture properties [18]. Moreover, it also found that the density and viscosity value are slightly increase due to the biodiesel content and the viscosity increasing proportional in trend to biodiesel composition $[18,19]$. The initiative is aim to reduce the environment damage from the carbon dioxide produced.

Microcrystalline cellulose (MCC) has a limitation that is needed for some applications compared to other natural polysaccharide polymers such as low wettability, moisture absorption, and limitation in processing temperature [1]. The previous research related to cellulose filled engineering thermoplastics, scientist believed that the use of cellulose as a reinforcement or additive did not give encouraging results as the materials exhibited severe discoloration and cellulose thermal degradation occurs at temperatures needed to process these engineering thermoplastics [20]. However, recently researchers have looked again at cellulose filled engineering thermoplastic suggested that MCC-filled nylon composites relevant in thermally challenging areas due to the higher mechanical properties and lower density such as engine covers, intake manifolds and radiator end tanks [21]. It is also essential to know and observe the temperature dependence due to the limitation of MCC in processing temperature in order to optimize the quality of final product and cost-effectiveness in variety of industrial process [1]. The viscosity value expects to decrease due to the increasing temperature for all liquids. However, modifications of viscosity value are essential as it could influence the operational cost of several stages in the industrial process such as mixing and fluid transport [22].

This study aimed to measure viscosity and observe the related properties of low concentration and temperature of microcrystalline cellulose (MCC) in water. Findings from this study could be fully utilized as a ground comparison in measurement technique between the rheometer and optical trapping technique on rheological properties of low concentration of a polymeric solution. Optical trapping technique offers possible measurement on such a solution at very low sample volume consumption. The previous study had been discussed about the potential of optical tweezer for microrheology measurement of variety polymeric solution [23]. It also highlights the advantages of optical trapping application as compared with the conventional method [23].

\section{Methodology}

The microcrystalline cellulose MCC in powder form (Sigma-Aldrich ${ }^{\circledR}$, Product No.310697) was dissolved in deionised water (DI water) with 4 different concentration; $0 \% w / w$ (DI water), $1 \% w / w$, 
$3 \% w / w, 5 \% w / w$ and $10 \% w / w$ as Figure 1 . The MCC solution was sonicated using a sonicator (Q sonica) and bathed using bath sonicator (Branson 2800) for process duration of 60 minutes. Sonication process is important in order to achieve a uniform condition of MCC solution [24].

Viscosity measurement in this study was conducted using the rheometer type AR-G2 series (TA Instrument) and $60 \mathrm{~mm} 1^{\circ}$ steel cone type of geometry (code: 992176). According to the manufacturer recommendation, the gap between geometry and Peltier plate, also known as truncation height, should be more or equal to tenth times particle sizes, as illustrated in Figure 2. In this study, the microcrystalline cellulose is $20 \mu \mathrm{m}$ in length, and the gap has been set up consistently for $200 \mu \mathrm{m}$.

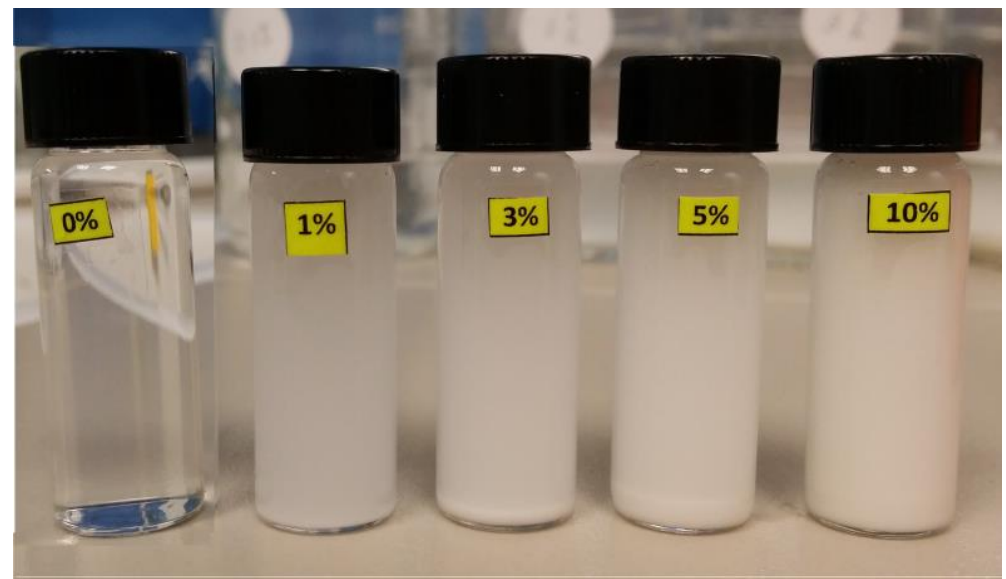

Fig. 1. Microcrystalline cellulose (MCC) diluted in deionised water with concentration of $0 \% w / w, 1 \% w / w, 3 \% w / w, 5 \%$ $w / w$ and $10 \% w / w$

The rheometer is used to monitor the displacement in time and converts it to shear rate. This rheometer is connected to the water circular in order to control the sample temperature by setting the required temperature from the $A R$ Instrument software. In order to have a right bearing of the moving geometry and to prevent friction, the installed geometry should go through the mapping and calibration process before taking any measurement [24].

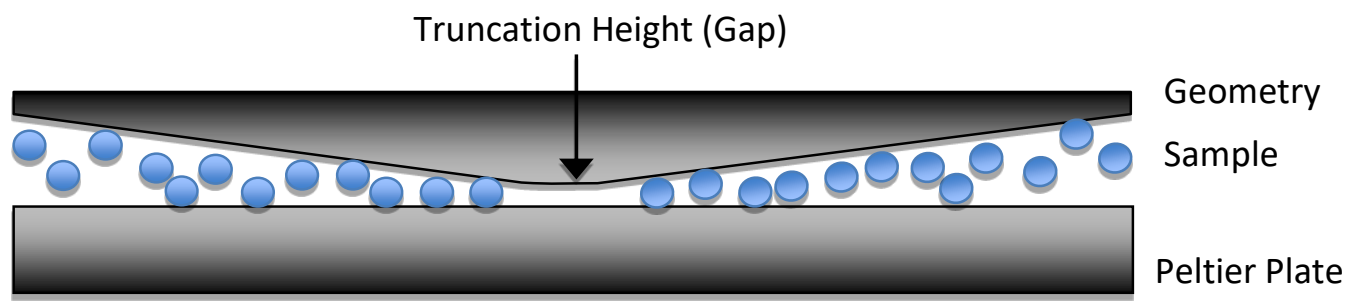

Fig. 2. The truncation height between cone type geometry and Peltier plate. Appropriate sample filling is advisable, avoid under or overfilling in order to have the correct measurement

The temperature of the sample condition was varied from $20^{\circ} \mathrm{C}$ to $30^{\circ} \mathrm{C}$, whose parameters of interest were being measured. A minimum of $1 \mathrm{ml}$ sample was required for each measurement and the measurement time was 120 seconds for each sample then repeated three times using a new sample. The deionized water was chosen as a benchmark to ensure the magnetic bearing rheometer worked appropriately during the measurement [25]. The viscosity measurement was 
validated using water as water has a well-known viscosity value then proceeded to the MCC sample. This validation aims to minimize fluctuation and reading errors.

\section{Results}

\subsection{Concentration Dependent}

The viscosities of the MCC solutions were measured at different concentrations and temperatures. It is observed that the rheological behaviour is highly influenced by the concentration of microcrystalline cellulose $[26,27]$. This viscosity value increased in trend to the concentration, as shown in Figure 3.

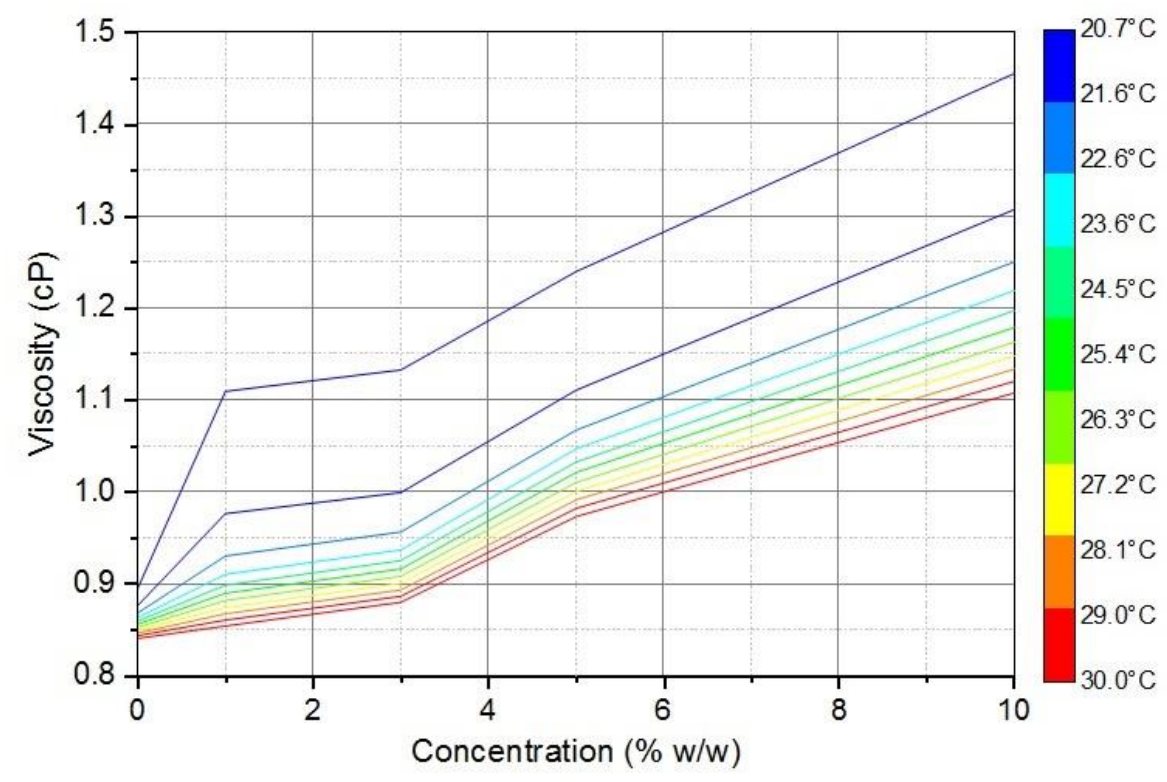

Fig. 3. The viscosity of microcrystalline cellulose solution at $0,1,3,5$ and $10 \% \mathrm{w} / \mathrm{w}$ as measured using a rheometer

Deionized water itself has a very low viscosity. However, an addition of a small amount of microcrystalline cellulose, which was well dispersed in the deionized water showed a logical trend even though cellulose hardly dissolved in water or oil. This indicated that the sonication process of MCC solution achieves uniform condition. A slight change in the viscosity value of MCC solution can be observed at a concentration of 1 to $3 \% \mathrm{w} / \mathrm{w}$. However, it drastically increased by $3 \% \mathrm{w} / \mathrm{w}$ and upward. According to the literature on the preparation, structure, and properties of microcrystalline cellulose, the aqueous suspension of a particular concentration of MCC could form a gel under the effect of shear force [28]. Besides, it also stated that the viscosity of MCC gel increased with increasing content of MCC in water and sharply increase of viscosity occurred in the 3-6\% $w / w$ concentration range [28]. This phenomenon showed that the internal resistance of the solution has increased as the solution more viscous [29].

\subsection{Temperature Dependent}

Findings for each concentration amount of MCC diluted in deionized water; the viscosity decreases as the temperature increased is illustrated in Figure 4. Even though the range of temperature varying is not too wide, but the effect can be seen as when the temperature increased 
the viscosity of MCC solution becomes decreased. The phenomenon is due to the MCC having higher thermal energy, and the binding forces are more easily able to weaken the attractive forces between them. According to the previous literature on the investigation of temperature-dependent structural changes in hydrogen bonds (H-bonds) in microcrystalline cellulose (MCC) by infrared (IR) and near-infrared (NIR) spectroscopy suggest that structural changes in the $\mathrm{H}$-bonds in the $\mathrm{O}_{3}-\mathrm{H}_{3} \cdots$ $\mathrm{O}_{5}$ intrachain $\mathrm{H}$-bonds in $\mathrm{MCC}$ gradually occur in the temperature region of $25^{\circ} \mathrm{C}$ to $130^{\circ} \mathrm{C}$, and it becomes continuously greater above $130^{\circ} \mathrm{C}[30]$.

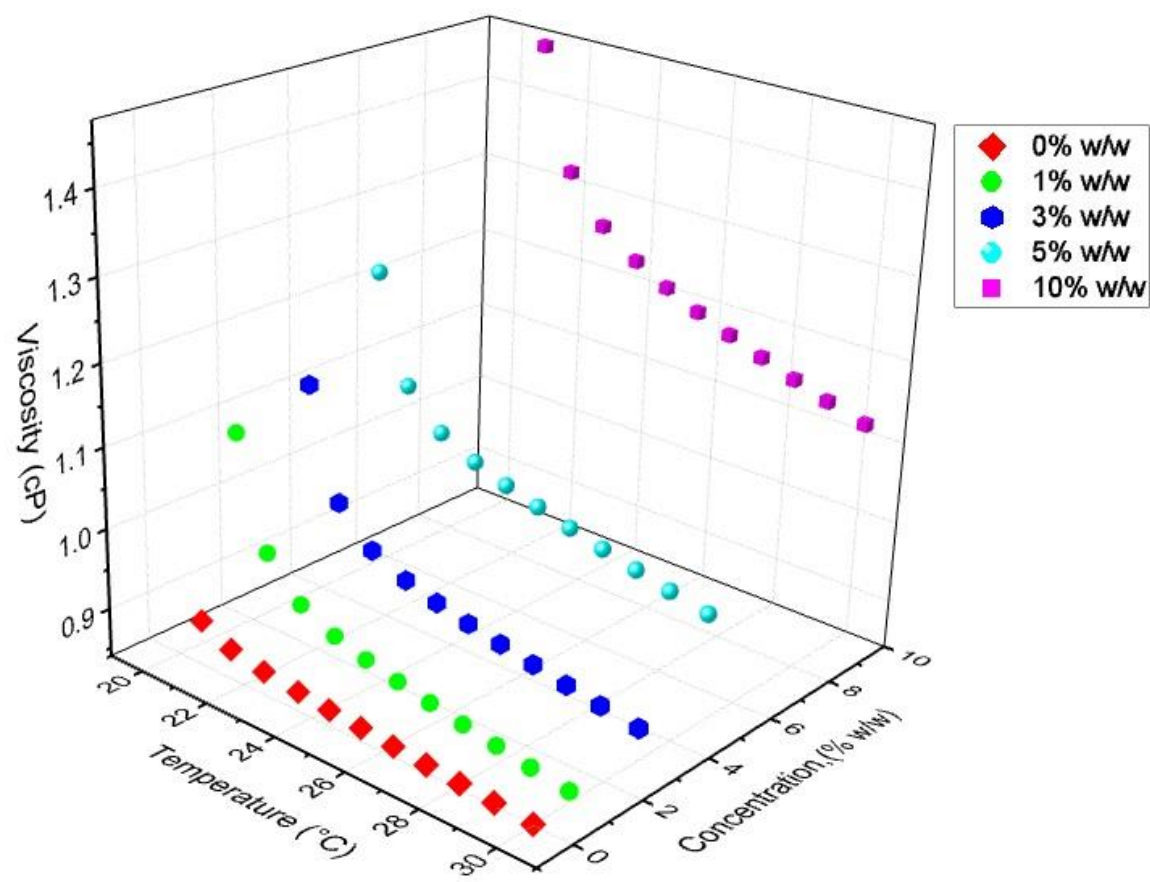

Fig. 4. Variations of viscosity with MCC concentration at different temperature

The viscosity values of MCC solution varying with concentration and temperature is in Table 1. The viscosity value summarised in the table is an average from the three times repeated data in $\mathrm{cP}$ unit while the temperature is represented in Celsius and MCC concentration in percentage.

Table 1

The viscosity values of MCC solution at different temperatures and concentrations of MCC

\begin{tabular}{|c|c|c|c|c|c|}
\hline \multirow[t]{2}{*}{ Temperature, $\mathrm{T}\left({ }^{\circ} \mathrm{C}\right)$} & \multicolumn{5}{|c|}{ Viscosity $(\mathrm{cP})$ Value for concentration, $\%(w / w)$} \\
\hline & 0 & 1 & 3 & 5 & 10 \\
\hline 20.7 & 0.8953 & 1.1093 & 1.1327 & 1.2397 & 1.4550 \\
\hline 21.6 & 0.8767 & 0.9765 & 0.9994 & 1.1107 & 1.3070 \\
\hline 22.6 & 0.8686 & 0.9305 & 0.9565 & 1.0673 & 1.2503 \\
\hline 23.6 & 0.8636 & 0.9106 & 0.9370 & 1.0470 & 1.2190 \\
\hline 24.5 & 0.8598 & 0.8987 & 0.9254 & 1.0327 & 1.1973 \\
\hline 25.4 & 0.8563 & 0.8899 & 0.9164 & 1.0213 & 1.1790 \\
\hline 26.3 & 0.8501 & 0.8820 & 0.9084 & 1.0107 & 1.1630 \\
\hline 27.1 & 0.8499 & 0.8745 & 0.9008 & 1.0008 & 1.1480 \\
\hline 28.1 & 0.8468 & 0.8677 & 0.8936 & 0.9914 & 1.1337 \\
\hline 29.0 & 0.8439 & 0.8609 & 0.8867 & 0.9822 & 1.1203 \\
\hline 30.0 & 0.8410 & 0.8545 & 0.8801 & 0.9734 & 1.1077 \\
\hline
\end{tabular}




\section{Conclusions}

The viscosity behaviour of microcrystalline cellulose (MCC) solution is highly dependent on the concentration and temperature. The viscosity was found to be drastically increased when the concentration was increased. However, the viscosity value decreased when the sample temperature was increased and trends differently as concentration before. In conclusion, the viscosity value is highly dependent on sample concentration and temperature within the described experimental conditions.

\section{Acknowledgement}

This research has been carried out under Research Acculturation Collaboration Effort (RACE 20150017-102-62) provided by the Ministry of Education of Malaysia. The authors would like to extend their gratitude to Universiti Pendidikan Sultan Idris (UPSI) that helped manage the grants.

\section{References}

[1] Trache, Djalal, M. Hazwan Hussin, Caryn Tan Hui Chuin, Sumiyyah Sabar, MR Nurul Fazita, Owolabi FA Taiwo, T. M. Hassan, and MK Mohamad Haafiz. "Microcrystalline cellulose: Isolation, characterization and bio-composites application-A review." International Journal of Biological Macromolecules 93 (2016): 789-804. https://doi.org/10.1016/i.ijbiomac.2016.09.056

[2] Vigo, Tyrone L., and Barbara J. Kinzig, eds. Composite applications: the role of matrix, fiber, and interface. VCH, 1992.

[3] Cataldi, Annalisa, Andrea Dorigato, Flavio Deflorian, and Alessandro Pegoretti. "Thermo-mechanical properties of innovative microcrystalline cellulose filled composites for art protection and restoration." Journal of materials science 49, no. 5 (2014): 2035-2044.

https://doi.org/10.1007/s10853-013-7892-6

[4] Rafiee, Zahra, and Valiollah Keshavarz. "Synthesis and characterization of polyurethane/microcrystalline cellulose bionanocomposites." Progress in Organic Coatings 86 (2015): 190-193.

https://doi.org/10.1016/j.porgcoat.2015.05.013

[5] Cataldi, Annalisa, Andrea Dorigato, Flavio Deflorian, and Alessandro Pegoretti. "Innovative microcrystalline cellulose composites as lining adhesives for canvas." Polymer Engineering \& Science 55, no. 6 (2015): 1349-1354. https://doi.org/10.1002/pen.24074

[6] Hoyos, Catalina Gómez, Emilien Cristia, and Analía Vázquez. "Effect of cellulose microcrystalline particles on properties of cement based composites." Materials \& Design 51 (2013): 810-818.

https://doi.org/10.1016/j.matdes.2013.04.060

[7] Bai, Wen, and Kaichang Li. "Partial replacement of silica with microcrystalline cellulose in rubber composites." Composites Part A: Applied Science and Manufacturing 40, no. 10 (2009): 1597-1605. https://doi.org/10.1016/i.compositesa.2009.07.006

[8] Choe, Deokyeong, Young Min Kim, Jae Eun Nam, Keonwook Nam, Chul Soo Shin, and Young Hoon Roh. "Synthesis of high-strength microcrystalline cellulose hydrogel by viscosity adjustment." Carbohydrate Polymers 180 (2018): 231-237.

https://doi.org/10.1016/i.carbpol.2017.10.017

[9] Peppas, Nicholas A., J. Zach Hilt, Ali Khademhosseini, and Robert Langer. "Hydrogels in biology and medicine: from molecular principles to bionanotechnology." Advanced Materials 18, no. 11 (2006): 1345-1360. https://doi.org/10.1002/adma.200501612

[10] Seliktar, Dror. "Designing cell-compatible hydrogels for biomedical applications." Science 336, no. 6085 (2012): 1124-1128. https://doi.org/10.1126/science.1214804

[11] Sun, Jeong-Yun, Xuanhe Zhao, Widusha RK Illeperuma, Ovijit Chaudhuri, Kyu Hwan Oh, David J. Mooney, Joost J. Vlassak, and Zhigang Suo. "Highly stretchable and tough hydrogels." Nature 489, no. 7414 (2012): 133-136. https://doi.org/10.1038/nature11409

[12] Zhao, Xuanhe. "Multi-scale multi-mechanism design of tough hydrogels: building dissipation into stretchy networks." Soft Matter 10, no. 5 (2014): 672-687.

https://doi.org/10.1039/C3SM52272E 
[13] Kamata, Hiroyuki, Yuki Akagi, Yuko Kayasuga-Kariya, Ung-il Chung, and Takamasa Sakai. "Nonswellable" hydrogel without mechanical hysteresis." Science 343, no. 6173 (2014): 873-875.

https://doi.org/10.1126/science.1247811

[14] Zhang, Xiaoqing, Xiaolin Wu, Dachao Gao, and Kenong Xia. "Bulk cellulose plastic materials from processing cellulose powder using back pressure-equal channel angular pressing." Carbohydrate Polymers 87, no. 4 (2012): 2470-2476. https://doi.org/10.1016/i.carbpol.2011.11.019

[15] Scatolino, Mário Vanoli, Danillo Wisky Silva, Lina Bufalino, Gustavo Henrique Denzin Tonoli, and Lourival Marin Mendes. "Influence of cellulose viscosity and residual lignin on water absorption of nanofibril films." Procedia Engineering 200 (2017): 155-161. https://doi.org/10.1016/i.proeng.2017.07.023

[16] Pouyet, Frédéric, Dominique Lachenal, Satyajit Das, and Christine Chirat. "Minimizing viscosity loss during totally chlorine-free bleaching of hardwood kraft pulp." BioResources 8, no. 1 (2013): 238-249. https://doi.org/10.15376/biores.8.1.238-249

[17] Sukamta, Sukamta. "Computational fluid dynamics (CFD) and experimental study of two-phase flow patterns gasliquid with low viscosity in a horizontal capillary pipe." CFD Letters 11, no. 8 (2019): 16-23.

[18] Maksom, Mohammad Syahadan, Nurul Fitriah Nasir, Norzelawati Asmuin, Muhammad Faqhrurrazi Abd Rahman, and Riyadhthusollehan Khairulfuaad. "Biodiesel Composition Effects on Density and Viscosity of Diesel-Biodiesel Blend A CFD Study." CFD Letters 12, no. 4 (2020): 100-109. https://doi.org/10.37934/cfdl.12.4.100109

[19] Benjumea, Pedro, John Agudelo, and Andres Agudelo. "Basic properties of palm oil biodiesel-diesel blends." Fuel 87, no. 10-11 (2008): 2069-2075. https://doi.org/10.1016/i.fuel.2007.11.004

[20] Caulfield, Daniel F., Rodney E. Jacobson, Karl D. Sears, and John H. Underwood. "Woodpulp fibres as reinforcements for high-melting engineering thermoplastics for "under-the-hood'automotive applications." The Polymer Processing. Montreal, Canada: The Polymer Processing Society (2001): 1-10.

[21] Kiziltas, Alper, Douglas J. Gardner, Yousoo Han, and Han-Seung Yang. "Mechanical properties of microcrystalline cellulose (MCC) filled engineering thermoplastic composites." Journal of Polymers and the Environment 22, no. 3 (2014): 365-372.

https://doi.org/10.1007/s10924-014-0676-5

[22] Aziz, Wan Nor Suhaila Wan, Shahrul Kadri Ayop, and Sugeng Riyanto. "The Potential Of Optical Tweezer (OT) For Viscoelastivity Measurement of Nanocellulose Solution." Jurnal Teknologi 74, no. 8 (2015). https://doi.org/10.11113/jt.v74.4722

[23] Wehrman, Matthew D., Seth Lindberg, and Kelly M. Schultz. "Quantifying the dynamic transition of hydrogenated castor oil gels measured via multiple particle tracking microrheology." Soft Matter 12, no. 30 (2016): 6463-6472. https://doi.org/10.1039/C6SM00978F

[24] Barnes, Howard A. "A handbook of elementary rheology. Institute of Non-Newtonian Fluid Mechanics." University of Wales (2000).

[25] Vajjha, Ravikanth S., Debendra K. Das, and Godwin A. Chukwu. "An experimental determination of the viscosity of propylene glycol/water based nanofluids and development of new correlations." Journal of Fluids Engineering 137, no. 8 (2015). https://doi.org/10.1115/1.4029928

[26] Qiao, Congde, Guangxin Chen, Jianlong Zhang, and Jinshui Yao. "Structure and rheological properties of cellulose nanocrystals suspension." Food Hydrocolloids 55 (2016): 19-25.

https://doi.org/10.1016/i.foodhyd.2015.11.005

[27] Rudraraju, Varma S., and Christy M. Wyandt. "Rheological characterization of Microcrystalline Cellulose/Sodiumcarboxymethyl cellulose hydrogels using a controlled stress rheometer: part I." International Journal of Pharmaceutics 292, no. 1-2 (2005): 53-61.

https://doi.org/10.1016/j.ijpharm.2004.10.011

[28] Jianan, Chen, Yan Shaoqiong, and Ruan Jinyue. "A study on the preparation, structure, and properties of microcrystalline cellulose." Journal of Macromolecular Science, Part A: Pure and Applied Chemistry 33, no. 12 (1996): 1851-1862. https://doi.org/10.1080/10601329608011011

[29] Romero, Carmen M., and Alejandro Beltrán. "Effect of Temperature and Concentration on The Viscosity of Aqueous Solutions of 3-Aminopropanoic Acid, 4-Aminobutanoic Acid, 5-Aminopentanoic Acid, 6-Aminohexanoic." Revista Colombiana de Química 41, no. 1 (2012): 123-131. 
[30] Watanabe, Akihiko, Shigeaki Morita, and Yukihiro Ozaki. "Temperature-dependent structural changes in hydrogen bonds in microcrystalline cellulose studied by infrared and near-infrared spectroscopy with perturbationcorrelation moving-window two-dimensional correlation analysis." Applied Spectroscopy 60, no. 6 (2006): 611618.

https://doi.org/10.1366/000370206777670549 